ARAŞTIRMA MAKALESI

RESEARCH ARTICLE

\title{
Türk Ceza Hukukunda Suç Üstlenme
}

\author{
False Confession in Turkish Criminal Law
}

Pınar Memiș Kartal ${ }^{*}$

\section{öz}

Adliyeye karşı işlenen suçlardan suç üstlenme, sık karşılaşılan bir suç tipidir. İftira ve suçluyu kayırma suçlarının özel biçimi olarak da nitelendirilen suç üstlenme, üstlenilen suçun gerçekleşmiş bir suçun üstlenilmesi ile gerçekte işlenmemiş, fakat uydurulmuş bir suçun üstlenilmesi ile gerçekleşebileceği ileri sürülse de tartışmalı bir suç tipidir. 5237 sayılı TCK'nın 270. maddesinde düzenlenen bu suçun Kanunda sayılan aileden kişilerin suçlarının üstlenilmesi şeklinde gerçekleşmesi halinde nemo tenatur ilkesinin dikkate alınarak şahsi cezasızlık sebebinin öngörüldüğü tespit edilmektedir.

Anahtar Kelimeler: Adliye, suç üstlenme, iftira, suçluyu kayırma, nemo tenatur.

\section{ABSTRACT}

Voluntary false confession is a srime against justice which is frequently encountered. It is a variation of the crimes of false accusation and protecting a guilty person. It can be committed by falsely confessing to a crime that was committed, or a made up crime that was never committed. It is a controversial type of crime. It is defined in Article 270 of the Turkish Penal Code No. 5237. Owing to the principle of nemo tenatur, committing this crime with the intention of protecting family members enumerated in the Article is personal grounds for waiver of penalty.

Keywords: Justice, false confession, false accusation, protecting a guilty person, nemo tenatur

\section{GENEL OLARAK}

Suç üstlenme, 5237 sayılı Türk Ceza Kanunu’nun özel hükümler kitabında, "Millete ve Devlete Karşı Suçlar ve Son Hükümler” başlıklı dördüncü kısmının “Adliyeye Karşı Suçlar” başlıklı ikinci bölümünde 270. maddede düzenlenmiştir. Buna göre:

\section{Suç Üstlenme}

\section{Madde 270 - (1) Yetkili makamlara, gerçeğe aykırı olarak, suçu işlediğini veya suça katıldığını} bildiren kimseye iki yıla kadar hapis cezası verilir. Bu suçun üstsoy, altsoy, eş veya kardeşi

\footnotetext{
* Doç. Dr., Galatasaray Üniversitesi Hukuk Fakültesi Ceza ve Ceza Usul Hukuku Öğretim Üyesi
}

Sorumlu Yazar/Correspondence Author: Pınar Memiş Kartal

E-posta/E-mail: pmemis@gsu.edu.tr

Geliş Tarihi/Received: $\quad 01.04 .2021$

Kabul Tarihi/Accepted: $\quad$ 15.06.2021 
cezadan kurtarmak amacıyla işlenmesi halinde; verilecek cezanın dörtte üçü indirilebileceği gibi, tamamen de kaldırılabilir.

Adliyeye karşı suçlardan biri olarak suç üstlenme, adli makamları yanıltmak suretiyle bunların yanlış karar almasına neden olunmaktadır. ${ }^{1} \mathrm{Bu}$ eylem ile maddi gerçeğin ortaya çıkartılmasına engel olunmakta, adil yargılanma hakkına bağlı temel haklar ihlal edilmektedir.

Suç üstlenme iftira suçunun özel bir görünümü olduğu da belirtilmekte ${ }^{2}$ ve doktrinde "kendi kendine iftira" olarak da nitelendirilmektedir ${ }^{3}$.

Kişinin suçu üstlenmek suretiyle adli makamları yanıltıp adil bir yargılama yapılmasını engellemesi ve işlemediği suçu buna rağmen üstlenmesi nedeniyle iftira suçu ile benzerlik taşıdı̆̆ı ileri sürülmektedir ${ }^{4}$. Suçu üstlenmede fail işlemediği bir suçu üzerine almaktadır; iftirada ise fiili işlemediğini bildiği bir kimseye hukuka aykırı bir fiil ya da suç isnat etmektedir. Dolayısıyla masum bir kimsenin haksız yere yargılanması yönünden bir benzerlik kurulabilecektir. Suçu üstlenmede üstlenilen eylem suç teşkil etmelidir, nitekim madde başlığı da bunu açıkça ifade etmektedir; iftirada isnat edilen fiilin hukuka aykırı olması yeterlidir suç teşkil etmesine gerek yoktur ${ }^{5}$.

Suç üstlenme suçuna ilişkin düzenlemede, suçun üstsoy, altsoy, eş veya kardeşi cezadan kurtarmak amacıyla işlenmesi halinde daha az ya da hiç ceza verilmeyebileceği öngörülmek suretiyle "nemo tenatur" 6 ilkesinin dikkate alındığı ve bu çerçevede şahsi cezasızlık sebebi öngörüldüğü tespit edilmektedir. $^{7}$

\section{A. TCK ILE ETCK KARŞILAŞTIRMASI}

Suç üstlenme suçu, 765 sayılı eski Türk Ceza Kanunu'nun, “Adliye Aleyhinde Cürümler” başlıklı üçüncü babın, "Suç Tasnii ve Resmi Mercileri İğfal” başlıklı ikinci faslında yer alan 283. maddesinin 2. fikrasında düzenlenmişti.

765 sayılı TCK m. 283’e göre, “Vuku bulmadiğını bildiği bir cürmü adliyeye veya keyfiyeti adliyeye tevdie mecbur olan bir makama vuku bulmuş gibi ihbar eden yahut vaki olmayan bir cürmün eserlerini takibata mübaşeret olunabilecek derecede uyduran kimse otuz aya kadar hapis cezasına mahkûm olur.

Adliye huzurunda sahte olarak bir cürüm işlediğini yahut bu cürme iştirak eylediğini söyleyen kimse hakkında dahi aynı ceza tertip olunur.” şeklinde düzenlenmişti.

ÜNVER Yener, Adliyeye Karşı Suçlar, Seçkin, Ankara, 2012, s.142.

SOYASLAN Doğan, Ceza Hukuku Özel Hükümler, Yetkin, Ankara, 2010, 694.

ARTUK Mehmet Emin - GÖKÇEN Ahmet - YENİDÜNYA Caner, Ceza Hukuku Özel Hükümler, 13. Baskı, Ankara 2013, 1117.

4 SEVÜK YOKUŞ Handan, Türk Ceza Hukuku Özel Hükümler, Adalet, Ankara 2019, 651.

5 ARTUK - GÖKÇEN - YENİDÜNYA, Ceza Hukuku Özel Hükümler, 1117.

6 ÜNVER, Adliyeye Karşı Suçlar, 142.

7 ARTUK - GÖKÇEN - YENIDÜNYA, Ceza Hukuku Özel Hükümler, 1117 
Suçu üstlenme suçu 765 sayılı TCK döneminde "kendi kendini itham" suçu olarak da nitelendirilmiştir. ${ }^{8}$

Eski ve mevcut TCK düzenlemelerinin karşılaştırılmasında eski düzenleme çerçevesinde korunan hukuki değerin Adliyeyi yanlı̧ yola sevk etmek olması dolayısıyla "Adliye" olarak belirtilmektedir9. Adli fonksiyonların korunduğunu belirten görüş de ifade edilmiştir. ${ }^{10}$ Bunun da günümüzde bu suçlar bakımından benimsenen değere yakın bir görüş olduğu söylenebilir. 5237 sayılı TCK bakımından da korunan hukuki değerin Adliye’nin itibar $1^{11}$ olarak ifade edilmesinin yanı sıra adil yargılanma hakkı olarak da belirtilmektedir. ${ }^{12}$

765 sayılı eski TCK'da suçu üstlenme suçunun meydana gelebilmesi eylemin Adliye huzunda gerçekleşmesi aranmaktayken, mevcut düzenlemede yetkili makam ifadesi kullanılmak suretiyle Adliye kavramından daha geniş bir ifade tercih edilerek suç yetkili olarak kabul edilen makamlar önünde işlenebilecektir. Bu makamlar 5271 sayılı CMK.m.158'de belirtilenlerdir. Eski düzenlemenin makamın tespiti yönünden açık ve belirli olması dolayısıyla yürürlükteki düzenlemeden daha yerinde olduğu belirtilmektedir. ${ }^{13}$

Her iki suçta da fail ve mağdur yönünden bir özellik bulunmamaktadır. Herkes tarafından işlenebilen bir suçtur. Bu iki düzenleme bakımından eylemin suç teşkil edebilmesi için faillerin suç şüphelisi ya da sanık konumunda bulunmaması gerektiği ifade edilmektedir. ${ }^{14}$

Her iki düzenlemede yer alan fiil seçimlik hareketli suç olarak düzenlenmiştir. 765 sayllı TCK bakımından failin Adliye huzurunda sahte bir suç işlediğini ya da bu sahte suça iştirak ettiğini beyan etmesi gerekirken; 5237 sayılı TCK da aynı yönde düzenlenmiştir.

Eski ve yürürlükteki düzenlemelerde suçu üstlenme neticesi hareket bitişik somut tehlike suçu olarak düzenlenmiştir.

Eski TCK düzenlemesinde yürürlükteki düzenlemeden süre olarak daha fazla ceza yaptırımı öngörülmüştür.

\section{B. KORUNAN HUKUKI YARAR}

Suçu üstlenme suçu ile korunan hukuki yarar adli makamların hataya düşürülmeleri sonucu verilecek hatalı kararlar sonucu kaybedecekleri itibar olarak ifade edilmiştir. ${ }^{15}$ Bir diğer görüşs suç üstlenme suçu ile korunan hukuki değeri adil yargılanma hakkı olarak ifade etmektedir. ${ }^{16}$ İnsan

8 ÖNDER Ayhan, Türk Ceza Hukuku Özel Hükümler, Filiz Kitabevi, İstanbul,, 1994, s.276.

9 ÖNDER, 276.

10 ÖZEK Çetin, Adliyeye Karşı Suçların Hukuksal Konusu, İ̈HFM 1997, C:LV, S.3, s.17-19.

11 SEVÜK YOKUŞ, s.651-652.

12 ÜNVER, s.34.

13 ÜNVER, s.145.

14 ÖNDER, s.276; SEVÜK YOKUŞ, s.652.

15 ARTUK/GÖKÇEN/YENIDÜNYA, s.1156.

16 ÜNVER, s.33. 
haklarını merkez alan bir yaklaşım ile adliyeye karşı işlenen suçlarda birey hak nesnesi olarak değil, hak süjesi olarak değerlendirilmesi gereği ile bunların düzenlenmesi ile korunan hukuki yararın adil yargılanma hakkı olduğunu söylemek isabetlidir. ${ }^{17}$

\section{SUÇUN UNSURLARI}

\section{A. MADDI UNSUR}

\section{Fail}

Suç üstlenme suçunun faili herkes olabilir. Kanun koyucu bu suç bakımından failde bir özellik aramamıştır. Ancak suçun faili hakkında bir soruşturma ya da kovuşturmasının bulunmaması gerekir. Suç üstlenme suçunun varlığı için failin kendi işlemediği, kendisine isnat edilmemi bir suçu üstlenmesi gerekir. ${ }^{18}$ Doktinde bir görüş ise "hakkında soruşturma ya da kovuşturma açılan merci dışında başka bir yetkili merciye başvurarak işlemediği suçu üstlenen kişinin eyleminin faillik unsuru açısından suç üstlenme suçunu” oluşturduğu gerekçesi ile hakkında soruşturma ve/veya kovuşturma açılmış kişinin suç üstlenme suçunun faili olamayacağı gerekçesine kısmen katıldığını ifade etmektedir. ${ }^{19}$

Adil yargılanma hakkının unsuru olarak susma hakkını kullanan kişinin suçun faili olamayacağı ifade edilmektedir. ${ }^{20}$ Gerçekten de kişinin sükût etmesi suçu kabullendiği anlamına gelmemektedir. Aksi bir anlam çıkartmak adil yargılanma hakkına, masumiyet karinesi aykırılık teşkil edecektir.

\section{Mağdur}

Suç üstlenme suçunun mağduru adil yargılanma hakkının sahibi kişi ya da kişilerdir. ${ }^{21}$ Adliye hukuksal değerin taşıyıcısı olması ile birlikte suçtan zarar gören sıfatını haizdir. ${ }^{22}$

\section{Suç Konusu}

Suç üstlenme suçunun konusu, "gerçeğe aykırı olarak işlemediği bir suçu üstlenme” dir.

\section{Hareket}

Suç üstlenme, yetkili makamlara gerçeğe aykırı olarak suçu işlediğini veya suça katıldığını bildirmek hareketleri ile gerçekleşmektedir. Bu suç seçimlik hareketli bir suç olup, neticesi harekete bitişik bir suçtur. Sırf hareket suçu olarak da ifade edilen suç üstlenmede fail gerçeğe aykırı olarak suçu işlediğini ya da suça iştirak ettiğini beyan edecektir. ${ }^{23}$

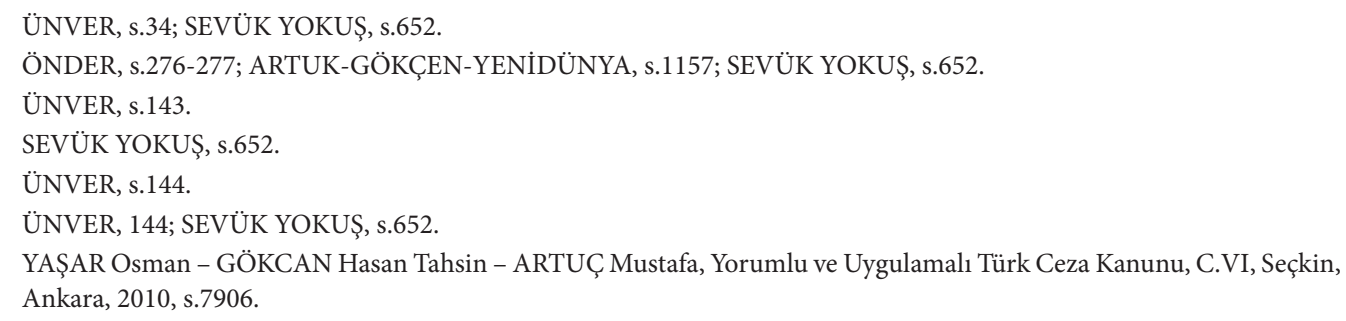


Failin gerçeğe aykırı olarak üstlendiği suç, işlenmiş bir suç olabileceği gibi, hiç işlenmemiş bir suç da olabileceği ifade edilmektedir. ${ }^{24}$ Ancak buna karşılık bir başka görüş TCK.m.270 düzenlemesinin lafzı çerçevesinde "suçta ve cezada kanunilik" prensibi gereği sadece işlenmiş ya da teşebbüs aşamasında kalmış suçlara uygulanabileceğini ifade ederek diğer türlü kabulün doğru olmadığını belirtmektedir ${ }^{25}$. $\mathrm{Bu}$ görüş ilgili düzenlemede; "bir suç işlediğini veya suça katıldığını" yerine, "suçu işlediğini veya suça katıldığını" ibaresinin kullanıldığını; her ne kadar maddenin başlı̆̆ı ve gerekçesinden dolayı adli makamları meşgul eden hayali suç uydurmalarda da suçu üstlenme suçunun oluşacağı ileri sürülse de, ortada işlenmiş veya kasten işlenen suçlarda suçun görünüş şekli ve yarıda kalmış hali olan teşebbüs aşamasında kalmış somut bir suçun varlığının gerekeceğini ileri sürmekte, fakat korunan hukuki yararı dikkate alarak hayali suçun üstlenilmesi yönünde değerlendirme yapma olanağı sağlayacak şekilde hüküm değişikliğine gidilmesi gerektiği de önermektedir ${ }^{26}$. Gerçekten de madde bir suçu işlediğini ya da suça katıldığını şeklinde düzenlemesi ile dar yorum ilkesi çerçevesinde bu şekilde yoruma elverişli olup, meydana gelmiş bir suçun üstlenilmesi şeklinde yorumlanması gerekir. Ancak madde gerekçesi ile birlikte gerek doktrindeki baskın görüş gerek Yargıtay suç üstlenme suçunda üstlenilen suçun işlenmiş olabileceği gibi, uydurma bir suçun da üstlenilmesi halinde TCK.m.270'in meydana geleceğini belirtmektedirler. ${ }^{27}$

Suçu üstlenmenin meydana gelebilmesi için failin üstlendiği fiilin suç olması gereklidir. Kabahat türünden bir fiilin üstlenilmesi bu suçu meydana getirmeyecektir. ${ }^{28}$ Üstlenilen suç şikâyete tabi olabilir, ancak bunun kovuşturulabilir bir fiil olması gereklidir. ${ }^{29}$

\section{Netice}

Suç üstlenme neticesi harekete bitişik bir suç olduğu için failin yetkili makamlara suçu işlediğini bildirmesi ile suç tamamlanır. Bu tip suçlarda nedensellik bağı bakımından bir tartışma da bulunmamaktadır.

Fail bir suçu işlediğini ya da bir suça katıldığına ilişkin bildirimi yetkili makamlar önünde yapmak zorundadır $^{30}$. Yetkili makam olarak da 5271 sayılı CMK.m.158'de belirtilenleri anlamak gereklidir. Buna göre ihbar ve şikâyet, Cumhuriyet Başsavcılı̆̆ına veya kolluk makamlarına yapılabileceği gibi, valilik veya kaymakamlı̆̆a ya da mahkemeye yapılan ihbar veya şikâyet, ilgili Cumhuriyet Başsavcılı̆̆ına gönderilir.

24 ÜNVER, 144.

25 ŞEN Ersan, “Suçu Üstlenme Suçu Özel Haller”, bkz. https://www.hukukihaber.net/suc-ustlenme-sucu-ozel-hallermakale,7922.html, erişim tarihi: 10.05.2021.

26 ŞEN Ersan, "Suçu Üstlenme Suçu Özel Haller”, bkz. https://www.hukukihaber.net/suc-ustlenme-sucu-ozel-hallermakale,7922.html, erişim tarihi: 10.05.2021.

27 ÜNVER, s.144; SEVÜK YOKUŞ, s.653.

28 TEZCAN-ERDEM-ÖNOK, s.1376.

29 YAŞAR-GÖKCAN-ARTUÇ, C.VI, s.7908.

30 ÜNVER, s.144-145. 
Ayrıca yine CMK.m.158’e göre, yurt dışında işlenip ülkede takibi gereken suçlar hakkında Türkiye’nin elçilik ve konsolosluklarına da ihbar veya şikâyette bulunulabilir.

Bir kamu görevinin yürütülmesiyle bağlantılı olarak suç üstlenen fail bunu ilgili kurum ve kuruluş idaresine ihbar veya şikâyet olarak yapabilir ve bu da gecikmeksizin ilgili Cumhuriyet Başsavcılığına gönderilir.

İhbar veya şikâyetin şekli yine CMK.m.158'de belirtilmiş, yazılı veya tutanağa geçirilmek üzere sözlü olarak yapılabileceği düzenlenmiştir.

765 sayılı eski TCK'da Adliye huzurunda ifadesi kullanılmak suretiyle belirli bir makam belirtilmişse de mevcut düzenlemede yetkili makamdan anlaşılması gerekenin ne olduğu konusunda bir açıklık Yargıtay içtihatlarında da bir birlik yoktur. ${ }^{31}$

\section{Teşebbüs}

Suç üstlenme suçu, seçimlik hareketli, neticesi harekete bitişik olması nedeniyle hareket yapıldığı anda meydana geldiği için teşebbüse elverişli değildir ${ }^{32}$. Suç yetkili makamlara bildirim ile gerçekleşir, ayrıca bir işlem yapılmasına gerek yoktur. ${ }^{33}$

Tüm neticesi harekete bitişik suçlarda olduğu gibi teşebbüs ancak hareket ile neticenin ayrılabildiği hallerde mümkün olabilecektir. ${ }^{34}$ İftira ile suç üstlenme suçunu değerlendirdiği bir kararında Yargıtay, “Sanık ..’’n, katılanın kullandığı aracın lastiklerini kestikten sonra, kardeşi ... ile görüşerek ...’in zarar verme suçunu üstlenmesini istediği, sanık ...’n da bu eylemine iştirak ettiği ..'n sanıklara suç üstleneceğini söylemesine rağmen Cumhuriyet Savcılığinda suçu üstlenmeyip olayın doğrusunu anlattığı somut olayda ...’n kabulü üzerine suçu onun işlediğini beyan eden sanıkların eylemlerinin suç üstlenme suçuna teşebbüs aşamasında kaldığg, gözetilmeden suç vasfında yanılgıya düşülerek iftira suçundan yazılı şekilde hükümler kurulması"'35 şeklinde verdiği bir kararında suçu üstlenmeyi tartışması yerinde olmakla birlikte kanaatimizce olayda teşebbüs aşaması da tartışmalıdır.

\section{B. MANEVI UNSUR}

Suçu üstlenme suçu kasten işlenebilen bir suçtur. Bu suçun taksirli hali öngörülmemiştir. Saik de aranmamıştır, dolayısıyla hâkim failin suçu işleme amacını sorgulamaz. Ancak suç üstlenme failin, üstsoy, altsoy, eş veya kardeşini cezadan kurtarmak amacıyla işlenmesi hali özel kastla işleneceğinden bu halde ancak saik önem taşıyacaktır.

31 ÜNVER, s.145.

32 DEMİRBAŞ, s.249.

33 Tezcan-Erdem-Önok, 1378.

34 ÜNVER, s.153; TEZCAN-ERDEM-ÖNOK, s.1378; SEVÜK YOKUŞ, s.659.

35 Yargitay 8. CD., E. 2017/18290, K. 2020/725, T. 14.1.202, karar için bkz., http:// www.kazanci.com/kho2/ibb/files/dsp. php?fn=8cd-2017-18290.htm\&kw=suçu+üstlenme+iftira\#fm, erişim tarihi 17. 07.2020. 
Suçun olası kastla işlenip işlenmeyeceği tartışılmıştır. ${ }^{36}$ Suç üstlenme suçunun olası kastla işlenmesi mümkündür ${ }^{37}$. Fail başkasının işlediği bir suçu üstlenmektedir, burada TCK.m.21 kapsamında öngörülen olası kast uygulama alanı bulabilecektir. Ancak şahsi cezasızlığı öngören hal bakımından özel kast arandığından burada olası kastın uygulanması mümkün olmayacaktır.

\section{HUKUKA AYKIRILIK UNSURU}

Suç üstelenme suçunun meydana gelebilmesi için failin gerçeğe aykırı olarak bir suçu üstlenmesi gereklidir. Bu nedenle meydana gelen suç gerçek ise failin bir hukuka uygunluk sebebi olarak ihbar hakkını kullandı̆̆ı gerekçesi ile eylem suç teşkil etmeyecektir. ${ }^{38}$

\section{SUÇU ETKILEYEN NEDENLER}

Şahsi cezasızlık hali olarak yakınlarının işlediği suçu üstlenme halini düzenlendiği TCK.m.270/ f.1'in ikinci cümlesinde ceza yargılamasının önemli bir ilkesi olan kişinin kendisini ya da yakınlarını suçlayıcı beyanda bulunmama hakkına bir diğer deyişle "nemo tenatur" ilkesine yer verildiği de ifade edilmektedir ${ }^{39}$. Bu hükümde failin yakınlarının işlediği bir suçu üstlenmesi durumda hâkim, failin cezasında indirime gidebileceği gibi ceza vermeyebilir. Kanun koyucu bu hükümde hâkime takdir hakkı tanımış, olayın niteliğine göre bir tercih yapabileceğini düzenlemiștir.

Suçu üstlenme bakımından öngörülen bu hükümde sayılan kişiler tahdidi olup, kıyas yolu genişletilemez. Eş ifadesi ile aralarında evlilik bağı bulunan kişiler anlaşılmalıdır. ${ }^{40}$

İstinaf mahkemesi tarafından incelenen bir olayda, "Sanıklardan A.Ü’nün eşinin yaptığı trafik kazası eylemini üstlenmesi ve diğer sanık I.Ü.nün ise sanık A.yı suç işlemeye azmettirdiği şeklinde gerçekleşen eyleminde TCK.m.270/1 ve 2. cümlesi gereğince; suç üstlenme ve bu suça azmettirme suçlarını oluşturduğu sonucuna varılmakla birlikte olayda şahsi cezasızlık sebebinin varliğı gerekçesi ile ceza verilmesine yer olmadı̆̆ına dair karar veren ilk derece mahkemesi kararında hukuka aykırılık görmediğinden esastan reddine" hükmetmiştir. ${ }^{41}$

\section{SUÇLARIN BIRLEŞMESI VE IŞTiRAK}

\section{A. SUÇLARIN BIRLEŞMESI}

Suç üstlenme suçu seçimlik hareketli bir suç olması nedeniyle, kanunda yer alan hareketlerin birini ya da hepsini gerçekleştirmiş olması fark etmeyecek, tek bir suç meydana geldiği için buna göre değerlendirme yapılacaktır.

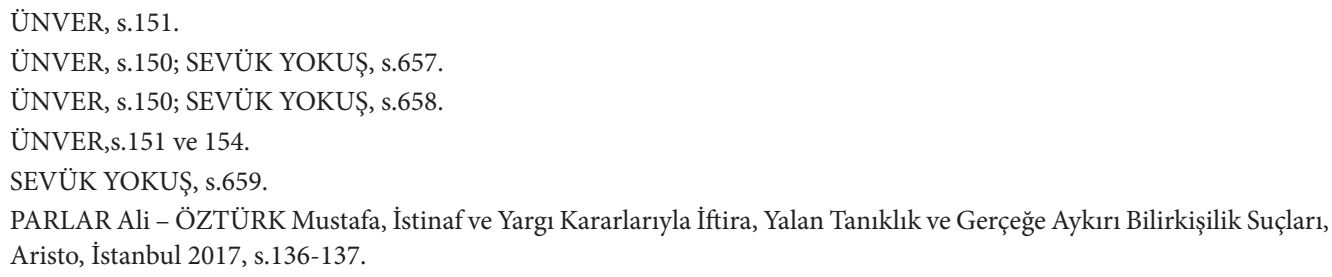


Suçların içtimaı bakımından özellik arz eden bir hal bulunmadığından uygulanabilen kurallar bu suç bakımından geçerlidir.

Bu suçta suçluyu kayırma suçu ile fikri içtima (TCK.m.44) oluşturan fiillere sıkça karşılaşılmaktadır. Yargıtay bir örnek olayda şu değerlendirmeyi yapmıştır: "Kaza nedeniyle inceleme dışı sanığın yaralanması nedeniyle takibi şikâyete bağlı olsa da olayda taksirle yaralama suçu oluştuğundan, sonuç itibarıyla yetkili makamlara gerçeğe aykırı olarak taksirle yaralama suçunu işlediğini bildirmiş sayılan sanığın eyleminin bu yönüyle "Suç üstlenme" suçunu oluşturduğu anlaşılmaktadır. Öte yandan sanığın gerçeğe aykııı olarak kazaya karışan aracı kendisinin kullandığını beyan etmekten ibaret eyleminin, 1,80 promil alkollü şekilde araç kullanan inceleme dışı sanık hakkında trafik güvenliğini tehlikeye sokma suçundan araştırma, soruşturma ya da kovuşturma yapılmasını engellemek suretiyle "Suçluyu kayırma" suçunu da oluşturduğu görülmektedir. Her iki suç tipi arasında özel norm-genel norm türünde bir görünüşte içtima ilişkisi de söz konusu olmadığından bu durumda TCK’nın 44. maddesinde düzenlenen "Fikri içtima" kuralı uyarınca işlediği bir fiil ile birden fazla farklı suçun oluşmasına sebebiyet veren sanığın, TCK’nın 270. maddesinde düzenlenen "Suç üstlenme" suçuna göre daha ağır cezayı gerektiren "Suçluyu kayırma" suçundan TCK 283/1. maddesi uyarınca cezalandırılması gerekmektedir." ${ }^{42}$

Suç üstlenme suçunun suçluyu kayırma suçunun özel biçimi olduğu doktrinde ifade edilmektedir ${ }^{43}$. Buna göre, kişinin yetkili makamlara, hem nesnel hem de öznel bakımdan gerçeğe aykırı olarak bir suçu işlediğini veya suça katıldığını; gerçeğe uygun olarak bir başkası hakkında yürütülen ceza soruşturmasında-kovuşturmasında veya infaz aşamasında bildirmesi, 5237 s. TCK’nın 283. maddesindeki "araştırma, yakalama, tutuklama, infaz"dan kurtulmayı sağlayııı bir İMKAN biçimi olması" gerekçesi ile suçluyu kayırmanın özel biçimi olarak kabul edilmektedir. ${ }^{44}$

\section{B. IŞTTiRAK}

Suç üstlenme suçu iştirakte özellik arz etmez. Özgü bir suç olmadığı için bu anlamda bunlara ilişkin kurallar da uygulanmaz, iştirake ilişkin genel düzenlemeler uygulanır. Bir başkasının suçunu üstlenen kişiyi azmettirip kendi işlediği suçu üstüne almasını sağlayan kişi de suç üstlenme suçunun azmettireni olarak hem üstlenilen suçtan hem de suç üstlenme suçundan yargılanıp, cezalandırılması gerekir. ${ }^{45}$ Yargıtay’n konuya ilişkin çok kararı bulunmaktadır. Buna örnek olarak yeni tarihli bir kararında Yargıtay; "..plakalı aracın, alkollü araç kullanmaktan ehliyeti elinden alınmış olan sanık ... adına kayıtlı olup 29.12.2012 tarihinde katılan ... şirketinden kasko sigortası yaptırmış olduğu, sanık ...'nın kasko tarihinden 1 gün sonra 30.12.2012 tarihinde ehliyetsiz olarak adına kayıtlı olan

42 YCGK, E. 2018/8-250, K. 2020/520, T. 15.12.2020, karar için bkz., https://lib.kazanci.com.tr/kho3/ibb/files/dsp. php?fn=cgk-2018-8-250.htm\&kw= `su\%C3\%A7+\%C3\%BCstlenme'+yetkili+makam\&cr=yargitay\#fm, erişim tarihi: 18.05.2021.

43 KIZIROĞLU KESKIN Serap, Suç Üstlenme Suçu (TCK.m.270), Suçluyu Kayırma Suçunun (TCK.m.283) Özel Şekli Midir?, makale için bkz., https://www.hukukihaber.net/suc-ustlenme-sucu-tck-270-sucluyu-kayirma-sucunun-tck-283ozel-sekli-midir-makale,7938.html, erişim tarihi: 12.05.2021.

45 ÜNVER, s.153. 
...plakalı aracını kullandığı ve kaza yaptığı, kazadan sonra çalışanı olan temyiz kapsamı dışındaki sanık ...'yı telefonla arayarak kolluk güçlerine kazayı kendisinin yaptığını beyan edip suçu üstlenmesi için azmettirdiği ve olay yerine gelen jandarma trafik ekiplerine araç şoförü olarak gerçeğe aykırı şekilde sanık ...'yı gösterdikleri, akabinde sanık ...nın katılan şirkete başvurup kasko ödemesi talep ettiği, kasko ekspertizlerince yapılan inceleme sonunda araçta bira şişlerinin bulunduğu, kaza tespit raporu ile aracın servis kayıtlarının uyumsuz olduğunun anlaşıldığı, ...’n da kazanın ehliyetsiz sanık ... tarafından yapıldığını itiraf ettiği ve bu sebeplerle sanığa kasko ödemesi yapılmadığı, sanık tarafından Susurluk Asliye Hukuk Mahkemesi’ne açılan alacak davasının 23.10.2014 tarihli gerekçeli karar ile reddine karar verildiği, bu şekilde sanık ...’ın üzerine atılı dolandırıcılığa teşebbüs, suç üstlenmeye azmettirme suçlarını işlediği anlaşılmakla, sanığın mahkumiyetlerine dair mahkemenin kabul ve uygulamalarında isabetsizlik bulunmamıştır” 46 . şeklinde verilen ilk derece mahkemesinin kararını onaylamıştır.

\section{YAPTIRIM VE YARGILAMA}

\section{A. YAPTIRIM}

Suç üstlenme suçunun yaptırımı iki yıla kadar hapis cezası olarak öngörülerek, üst sınır belirtilmiş, hâkime yaptırımın tayini hususunda bir takdir hakkı bırakılmıştır. Bunun da nedeni hükümde düzenlenen nemo tenatur ilkesini ortaya koyan şahsi cezasızlık ve indirim nedeni olarak değerlendirilmektedir. ${ }^{47}$

\section{B. YARGILAMA}

Suç üstlenme suçu re’sen kovuşturulan bir suçtur. Bu suç bakımından görevli mahkeme, 5235 sayılı Adli Yargı İlk Derece Mahkemeleri ile Bölge Adliye Mahkemelerinin Kuruluş, Görev ve Yetkileri Hakkında Kanun çerçevesinde (m.8 ve 12 ) asliye ceza mahkemesidir.

\section{KAYNAKÇA}

ARTUK Mehmet Emin - GÖKÇEN Ahmet - YENIDÜNYA Caner, Ceza Hukuku Özel Hükümler, 13. Baskı, Ankara 2013

GÖKÇEN Ahmet, Suç Tasnii ve Kendi Kendini İtham Cürümleri, İstanbul Barosu Dergisi, S. 2, İstanbul 2000

KİZIROĞLU KESKİN Serap, Suç Üstlenme Suçu (TCK.m.270), Suçluyu Kayırma Suçunun (TCK.m.283) Özel

Şekli Midir?, makale için bkz., https://www.hukukihaber.net/suc-ustlenme-sucu-tck-270-sucluyukayirma-sucunun-tck-283-ozel-sekli-midir-makale,7938.html, erișim tarihi: 12.05.2021

ÖNDER Ayhan, Türk Ceza Hukuku Özel Hükümler, Filiz Kitabevi, İstanbul, 1994.

46 Yargitay 15. CD., E. 2017/31415, K. 2021/1772, T. 23.2.2021, karar için bkz., https://lib.kazanci.com.tr/kho3/ibb/files/ dsp.php?fn=15cd-2017-31415.htm\&kw=`su\%C3\%A7+\%C3\%BCstlenme ' \&cr=yargitay\#fm, erişim tarihi: 21.05 .2021 . 
ÖZEK Çetin, Adliyeye Karşı Suçların Hukuksal Konusu, IÜHFM 1997, C:LV, S.3.

PARLAR Ali - ÖZTÜRK Mustafa, İstinaf ve Yargı Kararlarıyla İftira, Yalan Tanıklık ve Gerçeğe Aykırı Bilirkişilik Suçları, Aristo, İstanbul 2017.

SOYASLAN Doğan, Ceza Hukuku Özel Hükümler, Yetkin, Ankara, 2010.

ŞEN Ersan, "Suçu Üstlenme Suçu Özel Haller”, bkz. https://www.hukukihaber.net/suc-ustlenme-sucu-ozelhaller-makale,7922.html, erişim tarihi: 10.05.2021.

TEZCAN Durmuş-ERDEM Mustafa Ruhan-ÖNOK Murat, Teorik ve Pratik Ceza Özel Hukuku Seçin Ankara 2020.

ÜNVER Yener, Adliyeye Karşı Suçlar, Seçkin, Ankara, 2012.

YAŞAR Osman - GÖKCAN Hasan Tahsin - ARTUÇ Mustafa, Yorumlu ve Uygulamalı Türk Ceza Kanunu, C.VI, Seçkin, Ankara, 2010.

SEVÜK YOKUŞ Handan, Türk Ceza Hukuku Özel Hükümler, Adalet, Ankara 2019. 